\title{
Reduced expression of brain cannabinoid receptor 1 (Cnr1) is coupled with an increased complementary micro-RNA (miR-26b) in a mouse model of fetal alcohol spectrum disorders
}

\author{
Randa L Stringer, Benjamin I Laufer, Morgan L Kleiber and Shiva M Singh ${ }^{*}$
}

\begin{abstract}
Background: Prenatal alcohol exposure is known to result in fetal alcohol spectrum disorders, a continuum of physiological, behavioural, and cognitive phenotypes that include increased risk for anxiety and learning-associated disorders. Prenatal alcohol exposure results in life-long disorders that may manifest in part through the induction of long-term gene expression changes, potentially maintained through epigenetic mechanisms.

Findings: Here we report a decrease in the expression of Canabinoid receptor 1 ( $\mathrm{Cnr} 1$ ) and an increase in the expression of the regulatory microRNA miR-26b in the brains of adult mice exposed to ethanol during neurodevelopment. Furthermore, we show that miR-26b has significant complementarity to the 3'-UTR of the Cnr1 transcript, giving it the potential to bind and reduce the level of Cnr1 expression.

Conclusions: These findings elucidate a mechanism through which some genes show long-term altered expression following prenatal alcohol exposure, leading to persistent alterations to cognitive function and behavioural phenotypes observed in fetal alcohol spectrum disorders.
\end{abstract}

Keywords: Cannabinoid receptor 1, Epigenetics, Gene regulation, microRNA, Mouse, Neurodevelopment, Prenatal alcohol exposure

\section{Findings}

Fetal alcohol spectrum disorders (FASD) describe the continuum of phenotypic effects that may result from prenatal alcohol exposure (PAE). PAE is the most common cause of preventable neurodevelopmental disorders in North America [1,2] and is associated with attention deficit, impaired learning and memory, and hyperactivity [3], as well as an increased risk for anxiety and mood disorders [4]. These cognitive and behavioural changes persist throughout the life of an individual following PAE, though the mechanisms involved in maintaining these life-long changes are not well understood. However, it has been suggested that the effects of PAE may involve long-term changes in gene expression [5] that may be maintained through alcohol-induced epigenetic

\footnotetext{
*Correspondence: ssingh@uwo.ca

Department of Biology, Molecular Genetics Unit, Western University, London, ON N6A 5B7, Canada
}

changes. In particular, we have previously reported that the expression of microRNAs (miRNAs) may be globally altered in the adult mouse brain following PAE [6], which supports recent data by other groups $[7,8]$. More specifically, these changes in miRNA expression may subsequently alter the expression of target genes, with one miRNA having the potential to regulate many different genes [9]. One such gene may be cannabinoid receptor 1 (Cnr1).

We have previously shown that early neonatal ethanol exposure in mice results in reduced Cnrl gene expression in the adult brain [5]. Cnrl acts within the endocannabinoid $(\mathrm{eCB})$ system, involved in modulating neurophysiological processes controlling mood, memory, pain sensation, and appetite [10]. Cnrl is also thought to be involved in the neuropharmacological effects of alcohol [11] through inhibition of glutaminergic and GABAergic interneurons [12]. Variations in this gene or 
alterations in its expression are also associated with mood disorders, particularly fear and anxiety phenotypes [13].

Here, we use a C57BL/6J mouse model of binge-like exposure during the period of synaptogenesis [5] to assess a potential relationship between $C n r 1$ and its putative regulatory miRNA, $m i R-26 b$. We evaluated the inverse expression patterns of these two transcripts, hypothesizing that the up-regulation of the miRNA following PAE may in part be responsible for the observed reduction in transcript of a target gene in the adult brain. In these experiments, mice were exposed to two acute doses of alcohol $(5 \mathrm{~g} / \mathrm{kg})$ at neurodevelopmental times representing the human third trimester equivalent. This method has been previously reported and induces a peak blood alcohol level of over $0.3 \mathrm{~g} / \mathrm{dL}$ for 4 to 5 hours following injection, and is sufficient to induce neuronal apoptosis and result in FASD-related behaviour $[5,14,15]$. Our results suggest that ethanol exposure during neurodevelopment may exert its long-term effects by altering the expression of regulatory miRNAs, which may then reduce the expression of a number of target genes that may contribute to the spectrum of phenotypes observed in FASD.

Gene expression data previously was generated through microarray analysis (GEO \# GSE34539) of RNA isolated from whole brain tissue of 60-day-old male mice exposed to binge-like levels of alcohol during the third trimester equivalent on postnatal days 4 and 7 (see [5] for methods). miRNA expression array data (GEO \# GSE34413) was also generated from the same sample (see [6] for methods).
Analysis of these data show a reduction of Cnr1 (fold change $=-1.33, P=6.07 \times 10^{-5}$ ) in ethanol-treated brains as compared to the saline controls. Also, the miRNA miR$26 \mathrm{~b}$ increased in ethanol-treated mice (fold change = $1.284, P=0.0364$ ) compared to controls.

The potential interaction of the genes and miRNAs identified as differentially expressed by the array studies were analysed using Ingenuity's ${ }^{\oplus}$ Micro-RNA Target Filter. This analysis identified $m i R-26 b$ as a high-confidence predicted regulator of $C n r 1$ expression.

The reduction of Cnrl transcript was confirmed by real time RT-PCR [5], showing a 1.14-fold decrease in expression in ethanol-treated male brains as compared to matched controls ( $P=0.004$; Figure $1 \mathrm{~A})$. Further, we demonstrated a significant increase in the level of miR$26 b$ miRNA in ethanol-treated samples (fold change = 3.71, $P=0.012$ ) compared to matched controls (see [6] for methods) (Figure 1B). This inverse relationship within the same sample set suggests that the two observations may be biologically related. This potential interaction was further analysed using the TargetScan ${ }^{\circ}$ Human 6.2 predictor for miRNA targets [16], which shows that the seed region of $m i R-26 b$ possesses complementarity to the 3'-UTR of the Cnr1 transcript and has a significant potential to bind this region (Figure 2). The probability of conserved targeting $\left(\mathrm{P}_{\mathrm{CT}}\right)$ analyses the preferential conservation of binding sites [16]. It has the advantage of identifying targeting interactions that are not only more likely to be effective but also those that are more likely to be consequential for the animal, given the evolutionary conservation. The analysis
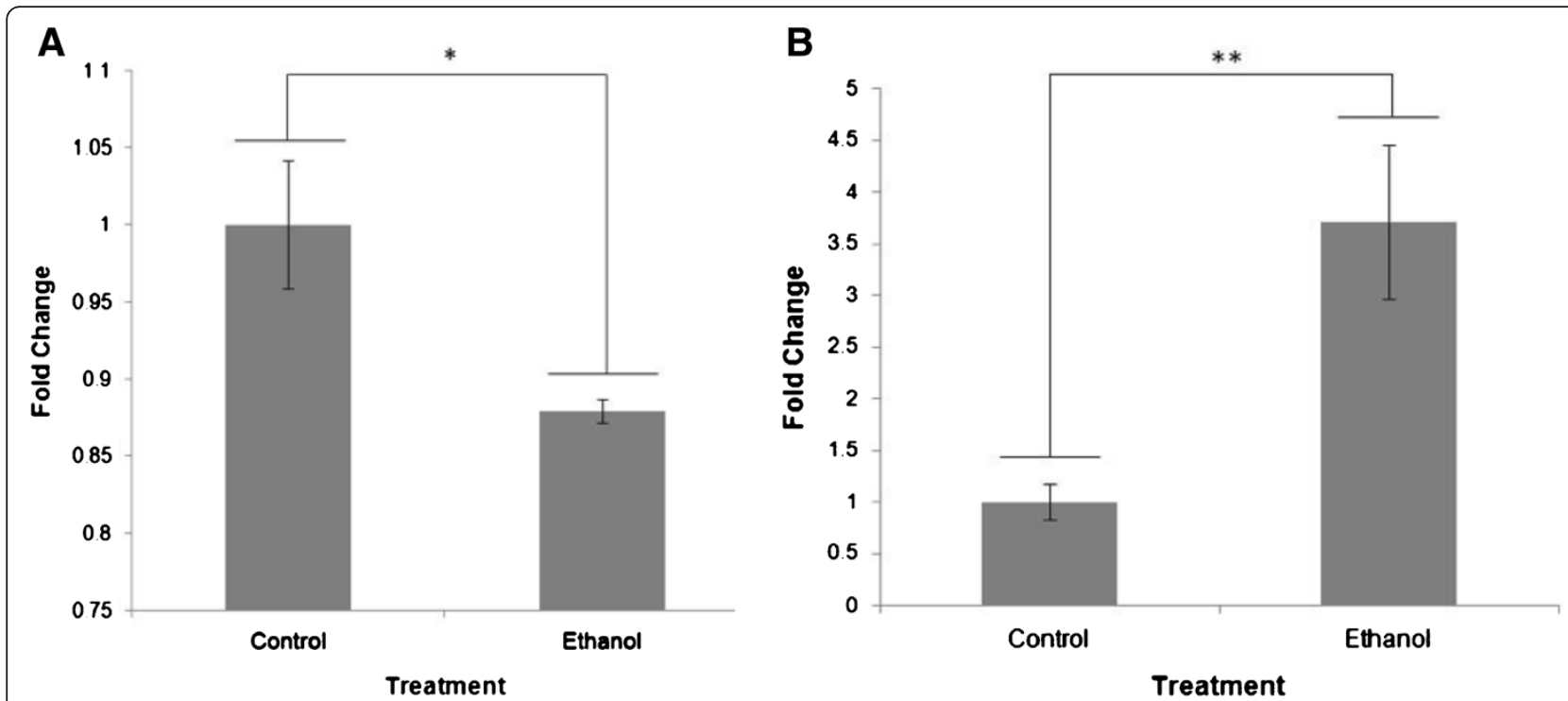

Figure 1 Analysis of Gene and miRNA expression via qPCR. (A) Change in Cnr1 mRNA levels in male control and alcohol-treated whole brain samples normalized to control. This figure was reproduced with permission from the authors [5]. (B) Change in miR-26b levels in male control and alcohol-treated whole brain samples normalized to control. Data are fold change \pm SEM. Control $n=5$, alcohol $n=5$. ${ }^{*} P<0.01$, ${ }^{* *} P<0.05$. 


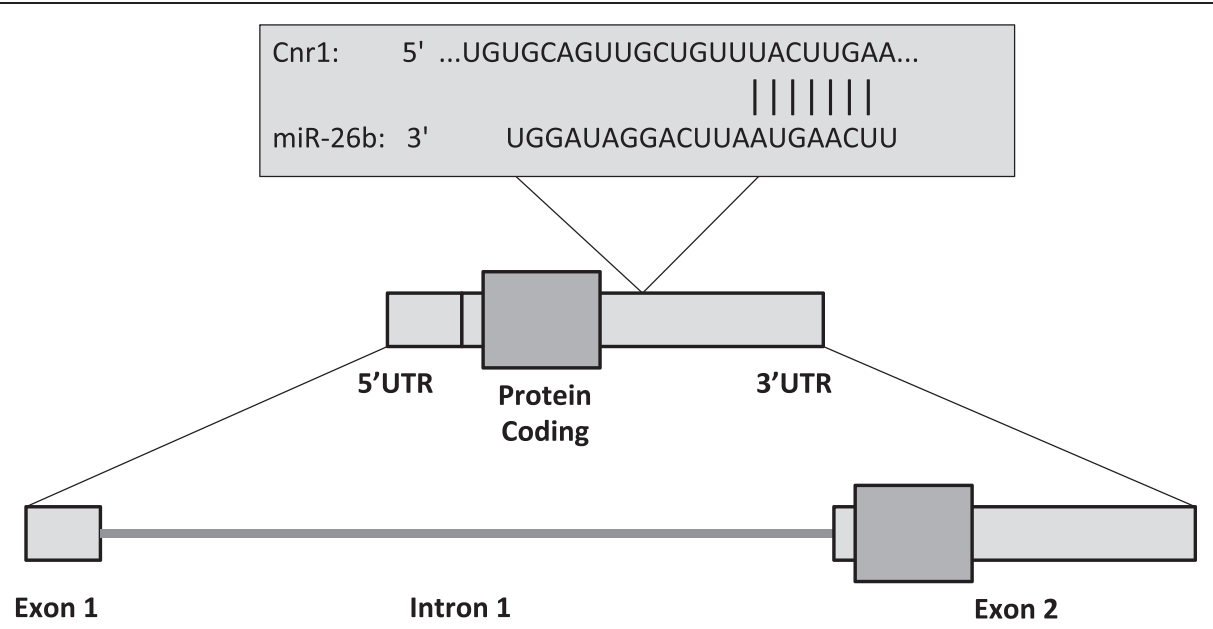

Figure 2 TargetScan ${ }^{\oplus}$ analysis of $m i R-26 b$-Cnr 1 binding sites provides a model for $C n r 1$ and $m i R$-26b interaction. The seed region of miR-26b has the potential to bind to the 3'-UTR of the Cnr1 transcript.

calculated a $\mathrm{P}_{\mathrm{CT}}$ score of 0.84 , which indicates a significant degree of confidence in the predicted interaction. Next, we evaluated expression of Cnrl and miR-26b to confirm their relative expression levels.

$m i R-26 b$ is encoded from an intron of small Cterminal domain phosphatase [17]. Interestingly, it is involved in neuronal differentiation as its transcription results in a negative feedback loop that is absent in neural stem cells [18]. $m i R-26 b$ has also been shown to regulate the expression of brain-derived neurotrophic factor $(B D N F)$, a gene strongly implicated in neurodevelopment and related disorders (i.e., schizophrenia) [19], including the effects of PAE [5].

This altered expression of miR-26b may have the ability to affect downstream gene expression by binding to the mRNA transcripts of its target genes. We have demonstrated that miR-26b shows complementarity to a region of the 3'-UTR of the Cnr1 transcript (Figure 2), which gives it the potential to regulate the expression of Cnr1. This regulation by miRNAs generally occurs through blocking of translation and/or promoting degradation of the target transcript [9]. The up-regulation of miR-26b correlates with the reduced Cnr1 transcript observed in the adult brain of mice neurodevelopmentally exposed to alcohol. [7] Our results suggest that this regulatory mechanism also occurs in vivo, and that the stable alteration of miRNA as a result of neurodevelopmental teratogenesis may affect longterm gene expression of its target transcript(s) long after exposure.

It is possible that relationships such as these may have the ability to influence the aberrant behavioural phenotypes seen in FASD. The eCB system, for instance, plays a strong role in anxiety-related behaviour [20], which has been shown to increase in adult mice following PAE [21]. Previous studies evaluating Cnrl knockout mice have demonstrated increased anxiety-like phenotypes [13]. This suggests that the observed reduction in Cnr1 expression demonstrated here may contribute to our observation of anxiety-like behaviour following PAE.

Ultimately, these findings provide a mechanism by which the long-term change in Cnr1 expression is maintained following PAE. They also suggest that the alteration of neurodevelopmentally-important miRNAs can influence the long-term function of biological pathways that influence cognition and behaviour. Epigenetic regulators of gene expression may then be affected by PAE, subsequently exerting pleiotropic effects on numerous gene targets that then contribute to the longterm and variable neurobehavioural effects associated with FASD.

\section{Abbreviations}

Cnr1: Cannabinoid receptor 1; eCB: Endocannabinoid; FASD: Fetal alcohol spectrum disorders; miRNA: microRNA; PAE: Prenatal alcohol exposure.

\section{Competing interests}

The authors declare no competing financial interests.

\section{Authors' contributions}

This project was developed by RLS, BIL, MLK, and SMS. MLK raised the mice, performed the experimental interventions, and extracted the RNA. RLS performed the GPCR reactions. BIL and RLS performed the bioinformatic analysis. RLS, BIL, MLK, and SMS wrote the manuscript. All authors read and approved the final manuscript.

\section{Acknowledgements}

The authors would like to thank David Carter from the London Regional Genomics Centre (LRGC) for hybridizing the expression array and aiding in the analysis. The authors would also like to thank Eric Diehl for providing a proofreading of the manuscript. 
Received: 7 May 2013 Accepted: 28 June 2013

Published: 2 August 2013

\section{References}

1. Chudley AE, Conry J, Cook JL, Loock C, Rosales T, LeBlanc N: Public Health Agency of Canada's National Advisory Committee on Fetal Alcohol Spectrum Disorder. Fetal alcohol spectrum disorder: Canadian guidelines for diagnosis. CMAJ 2005, 172(5 Suppl):S1-S21.

2. May PA, Gossage JP, Kalberg WO, Robinson LK, Buckley D, Manning M, Hoyme HE: Prevalence and epidemiologic characteristics of FASD from various research methods with an emphasis on recent in-school studies. Dev Disabil Res Rev 2009, 15(3):176-192.

3. Bhatara V, Loudenberg R, Ellis R: Association of attention deficit hyperactivity disorder and gestational alcohol exposure: an exploratory study. J Atten Disord 2006, 9(3):515-522.

4. Hellemans KG, Verma P, Yoon E, Yu W, Weinberg J: Prenatal alcohol exposure increases vulnerability to stress and anxiety-like disorders in adulthood. Ann N Y Acad Sci 2008, 1144:154-175.

5. Kleiber ML, Mantha K, Stringer RL, Singh SM: Neurodevelopmental alcohol exposure elicits long-term changes to gene expression that alter distinct molecular pathways dependent on timing of exposure. J Neurodev Disord 2013, 5(1):6.

6. Laufer BI, Mantha K, Kleiber ML, Diehl EJ, Addison SM, Singh SM: Long lasting alterations to DNA methylation and ncRNAs may underlie the effects of fetal alcohol exposure in mice. Dis Model Mech 2013, 6(4):977-992.

7. Wang LL, Zhang Z, Li Q, Yang R, Pei X, Xu Y, Wang J, Zhou SF, Li Y: Ethanol exposure induces differential microRNA and target gene expression and teratogenic effects which can be suppressed by folic acid supplementation. Hum Reprod 2009, 24(3):562-579.

8. Soares AR, Pereira PM, Ferreira V, Reverendo M, Simoes J, Bezerra AR, Moura GR, Santos MA: Ethanol exposure induces upregulation of specific microRNAs in zebrafish embryos. Toxicol Sci 2012, 127(1):18-28.

9. Mukherji S, Ebert MS, Zheng GX, Tsang JS, Sharp PA, van Oudenaarden A: MicroRNAs can generate thresholds in target gene expression. Nat Genet 2011, 43(9):854-859.

10. Pertwee RG: The pharmacology of cannabinoid receptors and their ligands: an overview. Int J Obes (Lond) 2006, 30(Suppl 1):S13-S18.

11. Adermark L, Jonsson S, Ericson M, Soderpalm B: Intermittent ethanol consumption depresses endocannabinoid-signaling in the dorsolateral striatum of rat. Neuropharmacology 2011, 61(7):1160-1165.

12. Elphick MR, Egertova M: The neurobiology and evolution of cannabinoid signalling. Philos Trans R Soc Lond B Biol Sci 2001, 356(1407):381-408.

13. Dubreucq S, Kambire S, Conforzi M, Metna-Laurent M, Cannich A, Soria-Gomez E, Richard E, Marsicano G, Chaouloff F: Cannabinoid type 1 receptors located on single-minded 1-expressing neurons control emotional behaviors. Neuroscience 2012, 204:230-244.

14. Ikonomidou C, Bittigau P, Ishimaru MJ, Wozniak DF, Koch C, Genz K, Price MT, Stefovska V, Horster F, Tenkova T, Dikranian K, Olney JW: Ethanol-induced apoptotic neurodegeneration and fetal alcohol syndrome. Science 2000, 287(5455):1056-1060.

15. Wozniak DF, Hartman RE, Boyle MP, Vogt SK, Brooks AR, Tenkova T, Young C, Olney JW, Muglia LJ: Apoptotic neurodegeneration induced by ethanol in neonatal mice is associated with profound learning/memory deficits in juveniles followed by progressive functional recovery in adults. Neurobiol Dis 2004, 17(3):403-414.

16. Friedman RC, Farh KK, Burge CB, Bartel DP: Most mammalian mRNAs are conserved targets of microRNAs. Genome Res 2009, 19(1):92-105.

17. Sowa N, Horie T, Kuwabara Y, Baba O, Watanabe S, Nishi H, Kinoshita M, Takanabe-Mori R, Wada H, Shimatsu A, Hasegawa K, Kimura T, Ono K: MicroRNA 26b encoded by the intron of small CTD phosphatase (SCP) 1 has an antagonistic effect on its host gene. J Cell Biochem 2012, 113(11):3455-3465.

18. Dill $H$, Linder $B$, Fehr A, Fischer U: Intronic miR-26b controls neuronal differentiation by repressing its host transcript, ctdsp2. Genes Dev 2012, 26(1):25-30.

19. Caputo V, Sinibaldi L, Fiorentino A, Parisi C, Catalanotto C, Pasini A, Cogoni C, Pizzuti A: Brain derived neurotrophic factor (BDNF) expression is regulated by microRNAs miR-26a and miR-26b allele-specific binding. PLoS One 2011, 6(12):e28656.
20. Ashton $\mathrm{CH}$, Moore PB: Endocannabinoid system dysfunction in mood and related disorders. Acta Psychiatr Scand 2011, 124(4):250-261.

21. Mantha K, Kleiber M, Singh S: Neurodevelopmental timing of ethanol exposure may contribute to observed heterogeneity of behavioral deficits in a mouse model of fetal alcohol spectrum disorder (FASD). J Behav Brain Sci 2013, 3:85-99.

doi:10.1186/1868-7083-5-14

Cite this article as: Stringer et al.: Reduced expression of brain cannabinoid receptor 1 ( $C n r 1)$ is coupled with an increased complementary micro-RNA (miR-26b) in a mouse model of fetal alcohol spectrum disorders. Clinical Epigenetics 2013 5:14.

\section{Submit your next manuscript to BioMed Central and take full advantage of:}

- Convenient online submission

- Thorough peer review

- No space constraints or color figure charges

- Immediate publication on acceptance

- Inclusion in PubMed, CAS, Scopus and Google Scholar

- Research which is freely available for redistribution 